\title{
Carpooling: facts and new trends
}

\author{
Chiara Bresciani, Alberto Colorni, Francesca Costa, \\ Alessandro Luè \\ of Poliedra - Politecnico di Milano \\ Milan, Italy
}

Abstract-The paper approaches the actual situation of carpooling, by reporting the most updated data divided by its different orms: private, corporate and urban carpooling. For this last kind some innovative experience are reported: instant carpooling, carpooling integrated with car sharing and with other transport modes. The potential of carpooling in the future scenario of disruptive technologies, such as the autonomous driving cars and the dynamic road charging is analyzed. Finally a proposal for some recommendations related to the user-centered approach and on the role of the different stakeholders.

Keywords-carpooling; users; integration; user-centered; autonomous cars; dynamic road charging.

\section{INTRODUCTION}

We are moving very quickly from public and private transport being separate businesses, to a more Integrated Multi Modal Mobility Network, due to changing demographics, preferences, and technology. The Future of Mobility consists of Technology enabled, door-to-door, multi-modal travel encompassing pre-trip, in-trip and post-trip services to improve journey experience to the Mobility User [1]

Carpooling is one of the most visible and rapidly evolving areas towards the paradigm shift from vehicle ownership to vehicle usage shared mobility, and therefore one of heightened importance, as it addresses the need of mobility of the population in contexts where the most traditional modes of transport are less effective [2].

According to the most commonly adopted taxonomy, carpooling is the agreement of joining the use of a private car by several individuals frequently commuting along the same journey at mutually compatible times [3]. Often used for commuting, carpools can be arranged between known or unknown parties. The first option is the simplest type of carpooling; in any other case, the system of carpooling becomes more complex, and requires flexible solutions for travelers. These solutions are often identified with the name of Real-time or dynamic ridesharing that matches drivers and passengers based on destination through a mobile app before the trip starts. The passenger is usually expected to pay a share of the trip cost.

Carpooling is of course also an old "technology," and many government initiatives have promoted carpooling for over half a century. In the 1940's an enormous conservation movement began to spread across the US, driven by the Government who sought to instruct and inspire each citizen, with vivid, powerful

\author{
Luca Studer \\ of Politecnico di Milano \\ Milan, Italy
}

messages of the dire need for every individual to take action, including using carpooling [4].

In Italy, carpooling was first introduced and promoted in the national legislation in 1998 with a law on sustainable mobility [5]. Over the last few years carpooling has seen a considerable increase, thanks to the diffusion of numerous web platforms that allow those seeking and/or offering a passage to meet and better define-plan the trip details.

\section{DIFFERENT FORMS OF CARPOOLING IN ITALY}

\section{A. The Italian situation}

The operator that dominates the Italian and European market for Personal Carpooling is currently the BlaBlaCar with more than 50 million users in 22 countries. Born in France in 2006 BlablaCar arrived in Italy in 2012. In 2017 BlaBlaCar had 2,5 million users and since 2012 1,5 billions of $\mathrm{kms}$ had been offered [6].

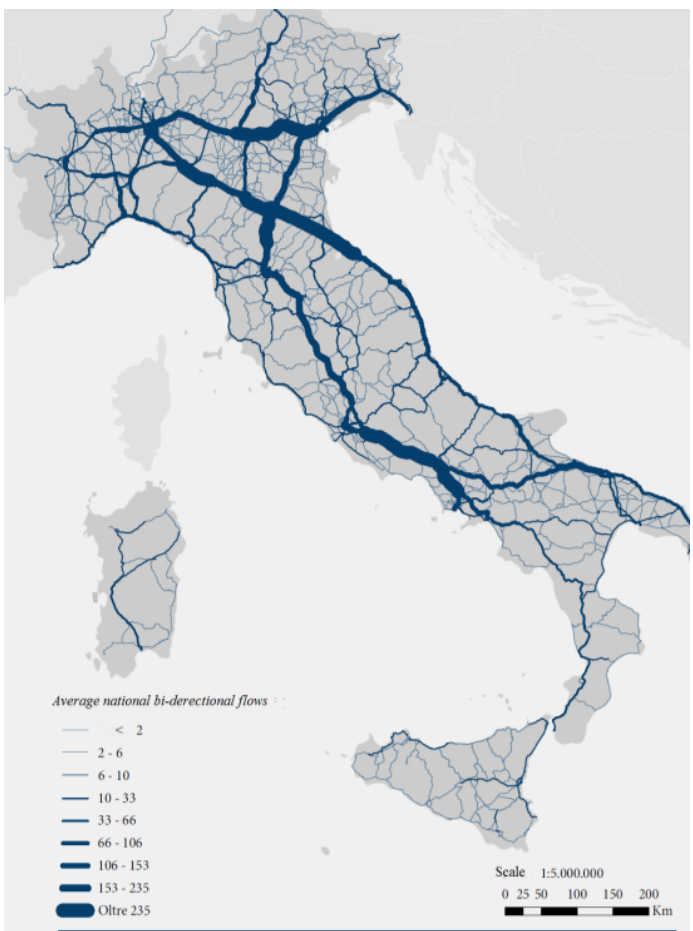

Figure 1: The average daily flow of carpooling travels in Italy [7]

The success of this kind of carpooling is linked to the weekly commuters that come back home in the weekend from the big urban areas. The most popular trips by carpooling are Milan-Genoa, Milan-Padua and Rome-Naples, but the average 
distance is of $340 \mathrm{~km}$ with an average cost of 18 euro. Italy dominates the ranking of the countries where carpooling is chosen for pleasure travels ( $26 \%$ of the Italian users).

The main reason to choose to carpool is the possibility to cut fuel costs and the social aspects, that allow to have interesting chats during the trip [7].

As far as corporate carpooling, this service is aimed at individual workers who need to travel at affordable prices without their car to reach the workplace and to companies. One of the main companies in the market for this service in Italy is Jojob, an Italian startup of the Politecnico of Torino, that has affiliated more than 100 big companies, more than 1.600 SMEs and about 120.000 employees registered to the service. The Jojob report "Corporate Carpooling 2017" [8] highlights that the workers who choose the carpooling have grown by $199 \%$, passing in a year from 20,000 to 59,738 . Shared trips have increased by $177 \%$, for a total of $1,714,120 \mathrm{~km}$ saved $(+164 \%$ on 2016). The positive effects are also on the environment with 222,835 kilos of CO2 less in the atmosphere.

From the "2017 Corporate Carpooling Report" developed by Jojob that, through a web platform and app on smartphone, allows employees of the same company or neighboring companies to certify the sharing of the car in the journey homework. In a year, workers who carpooled to work, have grown by $199 \%$ (from 20,000 to 59,738 ). Shared trips increased by $177 \%$ (from 16,500 in 2016 to 45,668 in 2017) and the number of kilometers saved were $1,714,120(+164 \%$ compared to 2016).

The carpooling company, in Italy, involves over 140,000 workers who choose to share the journey especially for comfort, stress reduction and chatter among colleagues. The majority of carpoolers are men $(58.8 \%)$ who are generally 35 years old, while women (41.2\%) are younger, with an average of 30 years. An average of 2.31 people traveling together on an average journey of $27.7 \mathrm{~km}$ per trip. In 2017 carpooling has produces a saving of 339.383 euros: 257.118 euros saved by passengers and 82.265 euros by drivers.

The carpooling service is used throughout Italy: a greater concentration is registered in the North $(50 \%)$ where the Lombardy region is the dominating one, followed by Emilia Romagna, Piedmont and Veneto. In the Center, however, the $35 \%$ of the companies promote the service, with Tuscany and Lazio among the most virtuous regions. On the other hand, there was an improvement in concentration in the South and in the Islands, which rose from $10 \%$ in 2016 to $15 \%$ (above all due to the strong growth of companies in Sardinia).

In terms of city ranking, Bologna is the most virtuous, followed by Modena and Milan, Turin, Florence, Rome, Venice, Belluno and Parma.

It seems that the corporate carpooling is a promising sector especially because trips are systematic and carpools are arranged by a shared platform and between known parties. This helps to overcome the social-psychological barriers, indicated, for instance, by the following motives: "Unsafe driving by other carpool members (level of driving ability)", "not liking or knowing the member/s of the carpooling group" [9].
Another emerging carpooling platform is BePooler with an application that, not only manages shared trips, but also the company incentives and reserve reserved parking spaces. With BePooler, a company of 1000 employees [10] can reduce the total distance covered by employees by $90,000 \mathrm{~km}$ in 12 months, with 10 tonnes of $\mathrm{CO} 2$ emitted less. In its first year in Italy BePooler, the innovative platform for company carpooling, has closed positively in 2017 and expects a 2018 growth

In its first year in Italy, BePooler has successfully closed the year 2017 and it expects a 2018 in further growth [11].

Members shared 30,000 trips, equal to $600,000 \mathrm{~km}$ saved, which have made it possible to avoid the emission of $78,000 \mathrm{~kg}$ of $\mathrm{CO} 2$. Over the last year, sustainable mobility has become an increasingly important issue for companies and institutions, on one hand to have better corporate welfare and to increase road safety, on the other to reduce the traffic generated by private cars by finding measures to increase air quality. More and more commuters are interested in the carpooling service and push their employers to adopt alternative mobility solutions that allow them to save on transport costs and optimize the journey to the workplace.

Also the institutions are realizing reducing car park area is a big saving. In order to facilitate growth and massive use, the Milan local authorities, following the example of what has already been set up in Lugano and Como, will dedicated carparks to carpooling at strategical multimodal hubs. For 2018, BePooler's goal is to expand its network in other important Italian cities and to export its business model to some of the largest European cities.

\section{TRENDS}

\section{A. Urban carpooling}

Carpooling in urban area is a third option that is more difficult to arrange but that has a big potential related to the fact that world's population is increasingly city-based. According to the United Nations [12], approximately two thirds of the world's population will be living in an urban area by 2050 . Today, $64 \%$ of all travel made is within urban environments and the total amount of urban kilometers travelled is expected to triple by 2050 .

The basic idea is that carpooling might solve the "last mile" problem (the distance between a mass transit station and final destination). Carpooling and long distance transport systems integrated in a multimodal network can provide the public with varied transportation options to fill the gaps in their travel journey. This indicates an opportunity for carpooling services and platforms to form partnerships with local governments.

In Italy an innovative experience is represented by the IShare Life project, co-financed as Close-to-market project under the call LIFE Environment \& Resource Efficiency. The aim is to demonstrate the technological and economic feasibility of e-car sharing models of service integrated with the carpooling model and combined with railway transport, tailored to smaller urban areas. The project is coordinated by FNM S.p.A., that is the company that owns both the car- 
sharing provider E-Vai and FerrovieNord, the railway infrastructure company. The I-Share project idea is to develop an user centered service that is tailored on the specific needs of these kind of urban areas. I-SharE mobility services will consist in new performance-based, non-ownership-based and highly customized value proposition for different customer segments in 5 different Business models. I-Share aims to support the application and deployment in a market with strong barriers at the entrance due to cultural behaviour, of an innovation that has already been demonstrated but not yet applied and deployed in the market. I-SharE actions, that include co-design and tuning activities, involve a validation not only of technical and economic performance, but also of new processes at systemic level, in operating conditions provided by the market). The project includes demonstration sites in Italy, in 4 small to mid-sized cities in Lombardy, and in Osijek, Croatia, characterized by different types of mobility demands and needs. The I-SharE Business Models are innovative carsharing services, that aim at maximizing the use of shared emobility during the daytime, either intermodally linked to public transport (railways, tramways and bus lines) or as an integration within Public Administration (PA) fleets applying the paradigm of Mobility as a Service. The aim is to demonstrate their practical and economic opportunities, to foster penetration of shared e-mobility in small- to mid-size urban areas and to facilitate behavioral change. Such services will improve customer mobility experience and quality of life, while reducing at the same time the cost of transportation and the overall environmental impact. They will also guarantee a return flow of electric vehicles for circular economy business.

A specific form of urban carpooling for instant - short distance is represented by the service offered by companies such as Uber and Lyft, that are more on-demand taxicab services that users appreciate for $\mathrm{t}$ the real-time monitoring.

A new MIT study [13] suggests that using carpooling options from companies like Uber and Lyft could reduce the number of taxis on the road $75 \%$ without significantly impacting travel time. MIT's Computer Science and Artificial Intelligence Laboratory (CSAIL) researchers developed an algorithm that found that 3,000 four-passenger cars could serve $98 \%$ of taxi demand in New York City, with an average waittime of only 2.7 minutes. Instead of transporting people one at a time, drivers could transport two to four people at once, results in fewer trips, in less time, to make the same amount of money. The team also found that $95 \%$ of demand would be covered by just 2,000 ten-person vehicles, compared to the nearly 14,000 taxis that currently operate in New York City. This research highlights that large-scale ride-sharing requires mathematical models and algorithms that can match large groups of riders to a fleet of shared vehicles in real time.

Other interesting examples in the USA are related to the collaboration between Uber and Rapid transit agencies such as the Metropolitan Atlanta Rapid Transit Authority (MARTA) that reached a cooperative agreement to improve their passengers" "last mile" problem. MARTA users can access the Uber app while using the public transit system to help them reach their final destination. Uber has reached a similar partnership with Dallas Area Rapid Transit (DART) to help create a solution for mobility issues within the city. The value added to users is the ease with which they are able to transfer between the two modes of transportation. These types of partnerships keep people moving through urban areas and demonstrate the importance of multimodal transportation initiatives [14].

Uber has recognized that multimodal transportation provides them with a huge opportunity to expand and build partnerships.

Another interesting news is related to the millions of people who live outside big city centers, in suburbs or regional towns. The main operator BlaBlaCar has recently re-engineered its search engine to return more local results for the searches, in order to match passenger requests with a sub-segment of drivers' planned route, by optimizing its service for the $85 \%$ of people that do not live near a central transport hub. This dynamically unlocks millions of possible local meeting points and, in effect, turns every highway across the country into a major transport line that can be joined at any point.

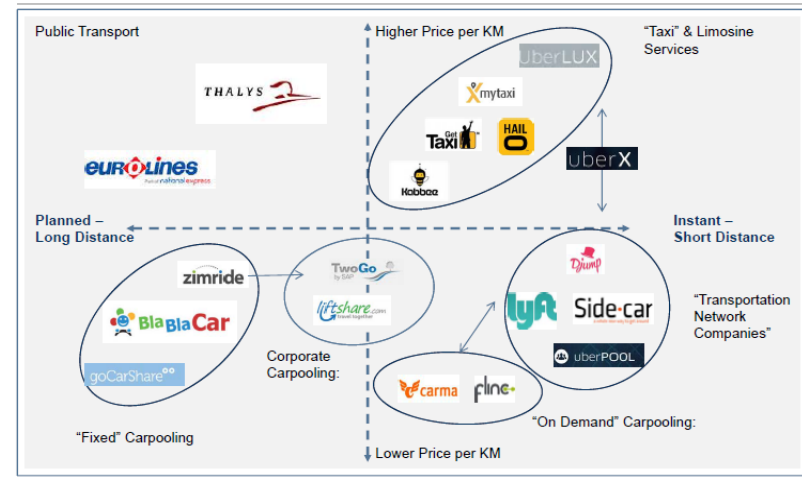

Figure 2: Comparative market positioning of ridesharing business models [13]

\section{B. The need of an user-centered service and future scenarios}

As previously evidenced, a multimodal system is necessary to solve transportation woes. It won't be a single solution, but a mixture of multiple transportation modes that allows urban mobility to reach its full potential. This can only be achieved if the public sector entities make a concerted effort to ensure that collaboration with private mobility providers results in services that work for people of all ages, incomes and mobility needs.

In both $\mathrm{B} 2 \mathrm{C}$ and $\mathrm{B} 2 \mathrm{~B}$ environments customers are demanding intuitive services; many actors investing significantly in order to deliver the seamless proposition and user experience.

As such services develop, it is indeed important to consider the needs also of future users to understand the possible longterm impacts on car ownership and travel behavior.

The future scenario must also consider the development of automotive technologies and possible applications that can strongly impact on carpooling. The market for transportation will be transformed by two emerging technologies [15]: autonomous driving cars and technology for dynamic congestion charging. 
The impact of self-driving cars on carpooling are related to the fact that eliminating the driver, the car do the effort to coordinate the possible routes and to organize all carpooling matches in real time (i.e., when the car is already moving) and adjust its route accordingly. For a human driver to accept a ride request when the car is already moving could be inconvenient or unsafe. The autonomous driver is always a reliable and safe carpool driver, costs are automatically charged.

With self-driving cars, intelligent systemwide road pricing also becomes more attractive, because convenient and affordable autonomous transportation may lead to increased congestion, since many people could be attracted to use the car instead of public transport. In such circumstances, intelligent systemwide road pricing becomes particularly valuable.

Another reason why self-driving technology makes road pricing more attractive is largely logistical, since it will be convenient to incorporate road pricing directly into the user interface for autonomous transportation. Furthermore selfdriving car's system collect a lot of data that can be used to compute tolls, at a very low marginal cost relative to the cost of developing the toll-collection infrastructure from scratch.

Autonomous transportation makes both road pricing and carpooling more convenient and attractive. Road pricing and carpooling reinforce each other: the former makes the latter more attractive, and vice versa.

Carpooling will become much more attractive in the world of self-driving cars, helping public and private transport to become two integrated businesses.

\section{CONCLUSIONS}

In summary, the different carpooling solutions can represent the potential to make a valuable contribution to making urban mobility more sustainable and support a new culture of car use. It's clear that carpooling is here to stay and is making an impact on the transportation industry. It is important for entrepreneurs to continue pushing the boundaries in creating new solutions to shape the future of transportation.

The public sector entities should make a concerted effort to ensure that collaboration with private mobility providers results in services that are designed around the different needs by using all the potential solutions offered by new technologies.

By connecting public transit with ride-sharing platforms, users have an alternative to using their private automobiles. If urban areas continue to adopt multimodal transportation, we might see a decrease in the number of households purchasing vehicles. This could be achieved by combining transit options into a seamless system to make travelling around a city easy, equitable and enjoyable.

In the near future, thanks to new technologies, social innovation and self-driving cars, carpooling will support the shift towards a Multi Modal Mobility Network, where carpooling will become much more attractive, blurring the line between solo driving and mass transit.

\section{REFERENCES}

[1] Briggs M., Future of Mobility: Introducing the New Business Models - Frost \& Sullivan's Intelligent Mobility Workshop 05/07/2015

[2] Galizzi M.M., The Economics of Car-Pooling: A Survey for Europe, 2004

[3] Luè A., Colorni A., "A software tool for commute carpooling: a case study on university students in Milan"in International Journal of Services Sciences 2(3/4) · January 2009

[4] http://www.ridebuzz.org/wartime_conservation

[5] Iacovini, C., Cafarelli, E., Mobility Management: il punto a 10 anni dal Decreto e prospettive future', 2008, Proceedings of the Ottava conferenza nazionale Mobility Management, Roma, Italy, March (in Italian).

[6] https://www.blablacar.it/stampa/comunicati-stampa/2-5-milioni-utenti1-5-miliardi-chilometri-offerti-blablacar-festeggia-primi-5-anni-delcarpooling-italia

[7] Beria P., Bertolin A., Il Carpooling in Italia: Analisi dell'Offerta. TRASPOL, 2016, Report 2/2016.

[8] JoJob, Report annuale 2017 di JoJob carpooling aziendale, 2018

[9] DeGruyter C., Investigating a CBD-wide carpooling scheme for Melbourne, 2006, Department of Infrastructure, Melbourne VIC, Australia

[10] www.bepooler.it

[11] www.affaritaliani.it/milano/bepooler-il-presente-le-prospettive-future521103.html

[12] United Nations, World urbanisation prospects, 2014

[13] Alonso-Mora J. Et al., 2017, On-demand high-capacity ride-sharing via dynamic trip-vehicle assignment, University of California, Santa Barbara, CA

[14] Nicoll E., Armstrong S., 2016, Ride-sharing: The rise of innovative transportation $\quad$ services, https:/www.marsdd.com/news-andinsights/ride-sharing-the-rise-of-innovative-transportation-services/

[15] Briggs M., Future of Mobility, Introducing the New Business Models Revolutionising Urban Mobility, Frost \& Sullivan's Intelligent Mobility Workshop, 1-2 July 2015

[16] Ostrovsky M., Schwarz M., Carpooling and the Economics of SelfDriving Cars, 2018 